\title{
User-centered DSS design and implementation
}

\author{
Jean-Claude Courbon \\ Institut National des Télécommunications \\ 9 rue Charles Fourier 91011 Evry-Cedex, France \\ Tel (33 1)60764577 Fax 60764493 Email courbon@int-evry.fr
}

\begin{abstract}
Methodologies for DSS design have traditionnally put the emphasis on the Decision, or the System, or the Support part of these systems. Illustrating it with two opposite case studies, this article tries to propose a rationale for a User-centered approach to DSS design and implementation. It stresses the importance of considering design, development and user participation as strongly related activities because DSS projects are change as well as learning processes, and communication is becoming paramount in a view of decision making taking place in more group-oriented and informal settings.
\end{abstract}

\section{Keywords}

Decision Support Systems, Design, Methodologies, Users

\section{INTRODUCTION}

Since the emergence of the first DSSs in the early '70s (Scott-Morton 1971, Gerrity 1975), researchers and practitioners have been working in various directions which could be summarized by the three letters composing the name of these new tools.

The Decision path was originated by Gerrity (1975), and later on by Keen and ScottMorton (1978) and Stabell (1988) among others. The interest in the Support aspect of DSS was linked with interactivity and dialogue which were investigated early on by Carlson et al (1977) and then by Sprague and Carlson (1982). This path culminated with the explosive development of microcomputing and spreadsheeting software in the '80s which made all these ideas commonplace and taken for granted. The greatest research line was in the System track 
and culminated with the emergence of the notion of DSS generators. The artificial intelligence field added to the emergence of so-called knowledge-based DSS (Bonczek et al, 1981) and recently software engineering development in the object-oriented direction have come into the DSS field too.

However, and readily from the start, the question about the methodology to design and implement DSSs immediately arose when building the first systems. As a computer application, there was something special about DSSs : they were aimed at managers instead of clerical workers. It followed that the methods used for conventional information systems were not adapted to final users who had the status in the organization to reject something they felt not useful or convenient enough. Designers and DSS project managers were not in a position to impose use of their developed systems, be it through compulsory measures, or training, or whatever means toward implementation and use of systems vital for the organization. This problem was first addressed by Ness (1975) and opened a line of research on methodologies adapted to this specific type of computer systems.

This paper will first look at the various methodologies which have been proposed for DSS. It will then focus on the idea of user-centered design and implementation by first looking at two case studies illustrating the outcome of opposed approaches to this user-orientation paradigm. In a third part, we will explore the rationale for this paradigm, and see how it fits into the foreseeable evolution of the DSS field.

\section{DSS DESIGN AND IMPLEMENTATION METHODOLOGIES}

\subsection{Decision-centered design methodology (Gerrity)}

Along with the development of an early DSS in the field of portfolio management, Gerrity came up with the first proposal for a design methodology adapted to decision support. Figure 1 summarizes this. Without going into details, this method emphasizes a sequence of phases somewhat similar to the systems analysis approach used in the information system field where the entry point is the analysis of the decision process for which a DSS is to be built.

The original aspect of this methodology is the early focus on obtaining both a descriptive and a normative model of decision making. The idea here is to grasp a good understanding of the decision behavior of the future users in order to provide them with the useful tools for supporting their decisions as they make them. But, at the same time, Gerrity insisted on arriving at a normative model of decision making, deriving it from the theory of the problem domain of the "good" way to take decisions. As an example for the portfolio management system, managers tended to make their investments and divestments in the portfolios managed by looking principally at the behavior of particular stocks or bonds. But the theory said that a change in a portfolio was to be considered in the perspective of the portfolio as a whole. The preferred information for the descriptive model was a graph of stocks, but the theory said that a graph of the content of a portfolio (growth vs revenues) had to be the primary information taken into account to make a decision. It follows that the DSS designed has to include tools for both models in order to induce future users to evolve toward the "good" decision making process. 


\begin{tabular}{|l|c|}
\hline Descriptive Model & $\begin{array}{c}\text { Decision System Analysis } \\
\text { Objectives and limits }\end{array}$ \\
\hline Problem Definition & Normative model \\
\hline Functional Model & New System Specification \\
\hline \multicolumn{1}{|c|}{ Model Behavior Simulation } \\
\hline Control System & New System Design \\
\hline \multicolumn{2}{|c|}{ Control and Adaptation } \\
\hline Implementation
\end{tabular}

Figure 1 Gerrity decision-oriented methodology.

\subsection{System-centered design methodology}

Another approach to DSS design comes from the software engineering field. At first, DSS design was viewed as the interconnection of a model base and a data base through a monitoring system to interpret user commands, mix the adequate data/model combination and present generated information. The question was at that time the efficient integration of software and communication .

With the arrival of artificial intelligence techniques applied to decision support, the architecture of DSSs became more a mix of rules and facts with an inference engine. The design of knowledge-based DSS was the process of knowledge acquisition, with many proposals to this difficult (in fact unsolved) task such as, for example, KADS.

More recently, object orientation in programming, method development and software engineering techniques has lead to new design methods like, for example, the vision of DSS as the assembly of component software (see Becker, 1993, for example).

\subsection{Support-centered design methodology (Sprague)}

Realizing that interactivity was a central part of DSS functionalities, Sprague (1982) proposed his ROMC approach. The design paradigm here is that dialogue design is the paramount task of the designer : thorough dialogue design, and its early implementation and testing, will be the basis to a clearer view for an eventual set of specifications for the future DSS.

More precisely, good dialogue design implies answering several questions. First, Representations have to be identified ; they are the mental images which the decider uses when following his decision process. These representations have to be put directly on the screen in order to provide the necessary support to the user. The second phase lies in the identification 
of Operations. They correspond to all the actions which the user carries out on the representations, and they have to be implemented directly in the context of the previous representations. They are verbs of the application, and they will become functions to be coded later. The last two phases refer to Memory - what the DSS should do to minimize the memorizing mental load of the user - and Control, which is the set of all the features which will allow the user to easily engage, wherever he/she may be in the dialogue, in any type of use of the system. Control should also be symetrically exerted by the system.

\subsection{User-centered design methodology (Ness, Courbon, Keen)}

As early as the mid '70s, Ness (1975) had shown that the question of DSS design was that of having it really used by organizations, not a trivial task for practitioners seeking an effective contribution of their DSS efforts. He proposed what he called the "middle-out" or "inside-out" approach, as opposed to traditional "top-down" or "bottom-up" approaches. Later, Courbon et al (Evolutive approach, 1979, 1980) and Keen (Adaptive design, 1981) went further in this direction.

The main principles of these appoaches are :

- Begin with the "crucial" decision problem, and try to provide quick help. The idea here is that the designer should engage as soon as possible in a dialogue with the user. Instead of formulating a grand plan based on agreed on specifications, the designer should come up with a quick solution to a limited aspect of the problem to be tackled in order to build trust into the designer/user relationship.

- Shorten as much as possible the life cycle of each version of the system being built. The traditional view of the life cycle of a system is a sequence of phases going from analysis to evaluation through design, coding, implementation and use. Instead of several months or years to go through these phases, the approach here claims that it should take only one month, one week, even a few days between analysis and evaluation.

- Evolve the system through multiple cycles. Obviously, such short life cycles cannot result in very much work done in a single life cycle. Therefore, the approach proposes a design and implementation strategy where the system evolves through several or many cycles. The assumption is that the user, being constantly present in the design process, at the use and evaluation phases, will probably come up with a clearer view of what he wants, or what he can expect.

- Evaluate constantly. This is a consequence of the strategy, where each version of the system being built is evaluated at the end of any cycle. The advantage is that more or less implicit objectives of the user become more obvious, his expectations are quickly visible, and he can envision new possibilities on a practical basis. The initial "crucial" problem can then be put in perspective (maybe it was not really that important, something else might then appear as more valuable in terms of decision support), and in the worst case, the system may abort quickly before too much work, money, time and energy have been put into a dead-end system.

The rationale behind such a user-centered approach to DSS design is that it is difficult to draw precise specifications for a DSS. Managers often do not have a "need" for a DSS, they just have a "desire". Moreover, they do not have a clear idea of what they really want, they just 
have a feeling that a DSS might help them. The challenge, for the designer, is then to built a system for people who just have a fuzzy idea of what they want. Therefore a methodology should refrain from targeting early on for specifications, these will appear progressively thanks to the prototype being progressively built.

It is interesting to note that such an approach has been advocated for DSS, whereas traditional business data processing systems needed more well-established methodologies based on systems analysis. However, a few years ago, even specialists of MIS have been promoting approaches close, in some respect, to the ideas presented above. Rapid Application Development, or RAD (Martin 1991) has become a buzzword outside of the DSS field.

Before going further into analysing the user-centered approach to DSS design, and looking at its implications in the evolving field of decision making in organisations, we will try to illustrate with two opposed case studies the difference between the user-centered approach and system- or decision-centered appoaches.

\section{CASE STUDIES}

\subsection{Case 1 : Planning of airline pilots stand by/training.}

In this case (Zarate 1991) the decision support needed was for the administrative staff in charge of distributing over a monthly timescale a given number of days for pilots to be assigned to stand by periods (being ready to take over sudden shortage of on-duty pilots) or for training. More precisely, this staff was given, at the beginning of the month, a certain number of 2-day to 6-day/pilot periods to schedule over the month. A representation of the total number of pilots either on duty, on holidays or on stand by/training is given in the following graph, where the "slack" on top of these cumulated assignments is the number of pilots in excess compared to the total number of available pilots (which varies depending on retirements, recruiting or long-term leaves of absence).

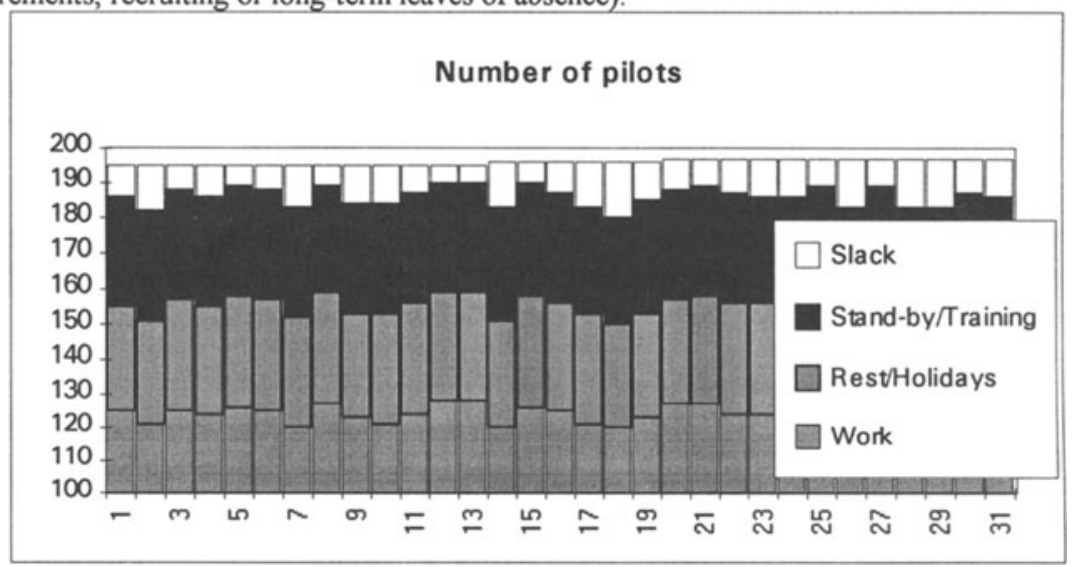

Figure 2 Various levels of pilots assignments 
The challenge for the planner was clearly to allocate these 2 to 6-day periods so that the slack would be as evenly distributed as possible over the 30 days of the month. The next graph shows the top of the preceding one, with a normalization of the total number of available pilots by making it flat at its level of the beginning of the month. Here the ideal result is shown where the slack is constant for the whole month. However, it is not an easy task (nor a totally feasible one depending on the numbers) to fill the black area with 2 to 6-days horizontal periods to attain this optimum result. The problem is also slightly more complicated because there are, at the beginning of each month, some remaining scheduled days left over from the previous month, and in the same way, some of the remaining load can be assigned to the next month.

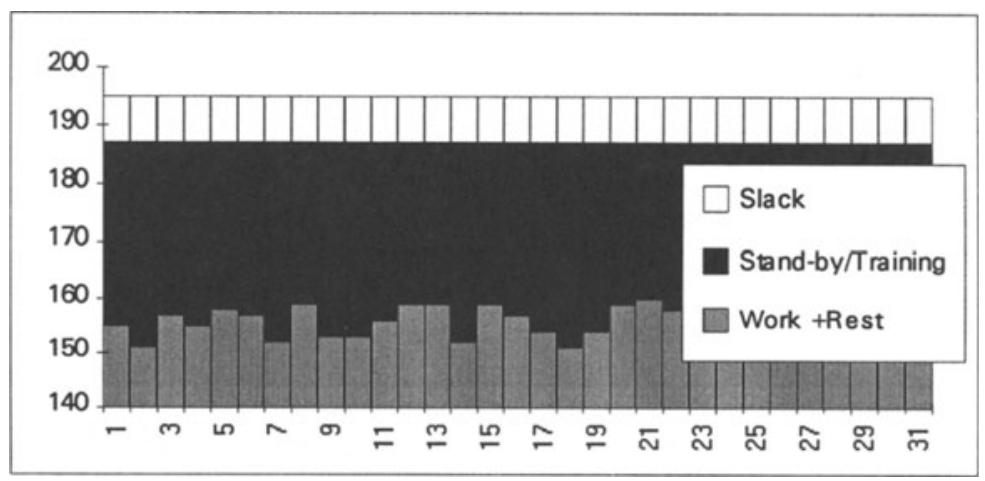

Figure 3 An ideal distribution of stand by/training load.

The DSS which was built considered the problem as an integer linear programming model with an objective function minimizing each day's difference from a constant slack. The planner was then able to adjust various parameters affecting constraints to generate more or less acceptable solutions.

This approach to decision support is somewhat far from the user's own understanding of the problem, and his/her interaction with the LP model parameters not very natural. Implementation and most notably, use of this system, were revealed to be problematic.

One can argue that building a DSS for this problem might have been more successful if the designers had tried to look at the problem from the decider's point of view. If they had followed Sprague's ROMC approach, they might have tried to discover the most familiar representation of the problem from the user's standpoint, and maybe found that the most powerful metaphor for this problem was actually similar to the well-known Windows game "Tetris". Indeed, the task appears as an intelligent game where the user "drops" blocks (here horizontal ones, 2 to 6 units large) onto the floor of a "lake" (in the above graph, the line "Work + Rest") in order to end up with a horizontal surface. Strategies could be devised (for example, begin with small "blocks" and fill the bottom of the lake), and support might have taken various forms (like filling the leftover "holes").

Although such a "user playing a game" approach might not have been so rewarding "scientifically" speaking from the designer's point of view, it is clear that it might have been more fruitful in terms of DSS success, user adoption and, in the end, effectiveness. 
However, if we look more globally into the chain of actors in this decision support problem, from management, which gives directions, to pilots who inherit the output of the system through designers of the DSS and their users, the reasons for the approach taken stems partly from an obvious Operations Research culture of the designers group. But more importantly, the approach followed illustrates a political struggle between the management and the pilots. Actually, the DSS has to show, in the end, that the total number of pilots in the company is too high (a constant slack is in fact the demonstration of this excessive slack). A solution buried in an O.R. setting is, from the administration's point of view, easier to use as an argument than a more simple (or simplistic) DSS that even pilots, or their representatives, could work with.

\subsection{Case 2 : Scheduling nurses in an hospital.}

In this case (Esaki 1995, Courbon and Esaki 1992), the DSS built was for the scheduling of nurses for a 4-week period across the various shifts in a ward. The head nurse's planning task was very cumbersome, due to the combinatorial nature of assigning nurses of different skills to night, afternoon and morning shifts and, at the same time, to the necessity of satisfying multiple constraints. It took several hours, even days, to build such a schedule and later on to adapt it to disturbances. The constraints come from different sources. Some of them are linked to union contracts, some others depend on the load of the ward which can change from season to season affecting the minimum requirements per shift. Moreover, nurses can be full-time or part-time employees and the head nurse tries to satisfy nurses' wishes in terms of days of work and/or type of shifts they prefer.

Without going into detail on the DSS which was built, it can be said that 1) design and implementation followed an "evolutive approach" - as exposed in 2.4 -, 2) object programming was the development environment (using Smalltalk), 3) the support given was based on the expertise of the head nurses in their decision processes and was incorporated into a knowledge-based system and, 4) interactivity and dialogue design were the early and central focus of the development process.

Figure 4 shows an example of a schedule generated by the DSS on which the head nurse could make changes and build alternatives interactively. Horizontally, the pool of available nurses (senior and junior) and assistants is represented, plus three lines for checking the scheduled vs required level of nurses per shift. The columns indicate the daily assignments of each employee over the 4-week period, coded by a number (type of shift) or a letter ( $\mathrm{V}$ for holidays for example).

Contrary to the previous case, the system developed here proved a success, and its use spread rapidly throughout the hospital, mainly thanks to its user-centered orientation from the beginning. Among many observations which were made in this case, we will present briefly some of the most interesting ones.

One of the first issues from the start was to elicit from the head nurse some kind of objective function which could measure the quality of a schedule in order for the DSS to be somewhat goal-oriented. It was almost impossible to get a response from the head nurse, and similarly she was very hazy when trying to explain why one version of a schedule might be better than another. Therefore, the designer began with the limited objective of building feasible schedules, and left it to the decider to improve it interactively toward an elusive 
evaluation of schedule quality. If the designer had insisted on getting clear evaluation measures (even qualitative ones) of schedule quality, he would probably have missed the point. Because, later, it appeared when observing the head nurses behavior with the DSS that what they looked for in a schedule was an expected "robustness", i.e. a schedule which would require minimal adjustments against foreseeable disturbances the ward was used to, like a nurse falling ill for example.

\begin{tabular}{|c|c|c|c|c|c|c|c|c|c|c|c|c|c|c|c|c|c|c|c|c|c|c|c|c|c|c|c|c|c|}
\hline Julie & 1992 & 23 & 20 & 27 & 20 & g & $x$ & 21 & 1 & 2 & 3 & 4 & 3 & 6 & 7 & 1 & 1 & 10 & 11 & 12] & i] & 14 & is & 16 & 17 & 11 & 19 & 20 & 21 \\
\hline & & & & & & & & & & & & & & & & & & & & & & & & & & & & & \\
\hline BALDI Corimue & Infirm 100 & 1 & 1 & 2 & 0 & 0 & 4 & 2 & 1 & 1 & 3 & 0 & 0 & 4 & 3 & 2 & 2 & 4 & 1 & 0 & 0 & 4 & 1 & 1 & 1 & 2 & 4 & 0 & 0 \\
\hline BANIOERGER & Infirm 100 & 4 & 2 & 3 & 4 & 1 & 0 & 0 & v & $v$ & $v$ & $v$ & $\mathbf{v}$ & 0 & 0 & 1 & 0 & 0 & 4 & 1 & 3 & 2 & 2 & 0 & 0 & 1 & 2 & 2 & 0 \\
\hline DOULLIN Nalhatie & lation 100 & 3 & 2 & 4 & 1 & 2 & 0 & 0 & 4 & 3 & 2 & 1 & 2 & 0 & 0 & 0 & 4 & 2 & 0 & 1 & 1 & 1 & $d$ & 2 & 2 & 0 & 0 & 4 & 1 \\
\hline URENON Darbara & Infiem 59.38 & 0 & 0 & 3 & 3 & 5 & 0 & 0 & 0 & 0 & 0 & 0 & $v$ & 0 & 0 & $v$ & 1 & $v$ & $\mathbf{v}$ & $v$ & 0 & 의 & $\mathrm{v}$ & 0 & 0 & 0 & 5 & 5 & 5 \\
\hline EUG:ENE Carule & Infirm 100 & 0 & 0 & 4 & 3 & 3 & 1 & 1 & 0 & 4 & 1 & 2 & 4 & 3 & 0 & 1 & 3 & 3 & 4 & 1 & 이 & 0 & 5 & 5 & 5 & 5 & 0 & 0 & 0 \\
\hline CiALLARD Annelle & Jufirm 100 & 4 & 3 & 0 & 2 & 1 & 3 & 0 & 0 & 0 & 4 & 3 & 3 & 1 & 1 & 3 & 0 & 0 & 5 & 5 & 5 & 5 & 01 & 0 & 0 & 4 & 1 & 3 & 2 \\
\hline JAUFFRED Heleme & linfirm 100 & 0 & 4 & 3 & 2 & \pm & $P$ & 0 & 2 & 2 & 0 & 0 & 1 & $r$ & 1 & 4 & 11 & 1 & 0 & 인 & 4 & 3 & 31 & 1 & 0 & 0 & 4 & $\boldsymbol{P}$ & 3 \\
\hline PETITJEAN Clianal & Infirm 100 & 2 & 4 & 1 & 1 & 0 & 0 & 1 & 3 & 0 & 5 & 5 & 5 & 5 & 0 & 0 & 0 & 1 & 2 & 2 & 01 & 0 & 01 & 0 & 4 & 3 & 3 & 1 & $\therefore$ \\
\hline POLASTRI Flereares & Derfirm 100 & 3 & 5 & 0 & 0 & 0 & 2 & 3 & 0 & 0 & 4 & 1 & 1 & 2 & 2 & 01 & 1 & 1 & 2 & 4 & 21 & 0 & 4 & 3 & 3 & 11 & 1 & 0. & 0 \\
\hline ROSSIER Dewise & Lefirm 31.25 & $\mathbf{0}$ & 0 & 0 & 0 & 0 & 3 & 3 & 3 & 5 & 0 & 0 & 0 & 0 & 3 & 5 & ; & 5 & 0 & 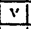 & 이 & 0 & vi & 11 & $v$ & $\begin{array}{ll} \\
\end{array}$ & $v$ & 0 & 0 \\
\hline CA1.DA.S & Aisfe 11100 & 0 & 0 & 7 & 7 & 6 & 6 & 6 & 0 & 6 & 7 & 7 & 1 & 0 & 0 & 6 & 6 & 1 & 1 & 1 & 0 & 0 & $\therefore$ & 6 & 1 & 0 & 0 & 11 & 1 \\
\hline CARlBO Anyerorn & Aide 11100 & 7 & 7 & 1 & 1 & 6 & 0 & 0 & 6 & a & 6 & 1 & $v$ & 0 & 0 & 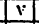 & v & $\dot{1}$ & $y$ & $v^{\prime}$ & 0 & 0 & 1 & iv & $y$ & v) & $v$ & 0 & 0 \\
\hline FEKNAANDLS.0U.1' & Aide II 100 & 6 & 6 & 0 & 0 & 1 & 1 & 1 & 1 & 1 & 7 & 0 & 0 & 7 & 7 & 7 & 7 & 1 & 0 & 0 & 11 & 1 & 11 & 1 & 6 & 0 & 6 & 0 & 0 \\
\hline KOORIGUEZ & Aisle II KO & 7 & 1 & 6 & 6 & 0 & 0 & 0 & 0 & 0 & 0 & 6 & 6 & 6 & 1 & 0 & 0 & 0 & $i$ & 7 & 1 & 5 & 01 & 01 & 0 & 1 & 1 & 7 & 7 \\
\hline REGUEIRO Maria & Emplas 100 & 2 & 2 & 2 & 2 & 2 & 0 & 0 & 2 & 2 & 2 & 2 & 2 & 0 & 0 & 2 & 2 & 2 & 2 & 2 & c) & 0 & 21 & 2 & 2 & 2 & 2 & 01 & 0 \\
\hline & & & & & & & & & & & & & & & & & & & & & & & & & & & & & \\
\hline Night & & 1 & 1 & 1 & 1 & 1 & 1 & 1 & 1 & 1 & 1 & 1 & $!$ & 1 & 1 & 1 & 1 & 1 & 1 & 1 & 1 & 1 & 1 & 1 & 1 & 1 & 1 & 11 & 1 \\
\hline Afternoon & & 2 & 2 & 2 & 2 & 2 & 1 & 1 & 1 & 1 & 2 & 1 & 2 & 1 & 1 & 2 & 2 & 2 & 2 & 2 & 1 & 1 & $:$ & 1 & 1. & $:$ & 2 & 11 & 1 \\
\hline Morning & & 3 & 1 & 4 & 1 & 3 & 3 & 3 & 1 & 1 & 3 & 3 & 1 & 3 & $\mathrm{~J}$ & 3 & 3 & 4 & 3 & 3 & 3 & 3 & 3 & 3 & 3 & 3 & 4 & 3 & \\
\hline Aistes & & 3 & 3 & 3 & \begin{tabular}{l|} 
\\
\end{tabular} & 3 & 2 & 2 & 21 & 3 & 3 & 3 & 2 & 2 & 2 & 2 & 2 & 2 & 2 & 2 & \begin{tabular}{|l|}
2 \\
\end{tabular} & 2 & 21 & 12 & 2 & 12 & 2 & 2 & \\
\hline
\end{tabular}

$1=7: 00 \mathrm{am}-3: 30 \mathrm{pm}$

$2=7: 00 \mathrm{am}-12: 00 \mathrm{am}$ and $2: 30 \mathrm{pm}-5: 00 \mathrm{pm}$

$3=7: 00 \mathrm{am}-12: 00 \mathrm{am}$ and $6: 00 \mathrm{pm}-9: 00 \mathrm{pm}$

$4=1: 30 \mathrm{pm}-10: 15 \mathrm{pm}$

$\mathrm{O}=$ day-off

$5=9: 45 \mathrm{pm}-7: 15 \mathrm{pm}$

$6=7: 00 \mathrm{am}-11: 30 \mathrm{am}$ and $2: 30 \mathrm{pm}-6: 00 \mathrm{pm}$

$\mathrm{V}=$ holiday

$\mathrm{P}=$ problem

Figure 4 A 4-weeks schedule (taken from Esaki, 1995).

Another observation had to do with the effort made to fill the DSS with as much expertise from the head nurses as possible in order to provide better support. Looking into the way they interactively modified solutions generated by the system under construction, the designer was able to put forward some rules they applied and that were included in the knowledge-based system. But in this process, it was discovered that a lot of this "expertise" had to do with what has to be called "private" knowledge. What should be done with remarks like "Mary already dodged Christmas and New Year, she has got to be on duty for Easter" or "Jane and Ann's relationship has deteriorated, better not put them on the same shift" ? Going too far into capturing the expert knowledge, especially the private one, most of the time can be a neverending quest, and in some cases, an unjustified pursuit. A DSS has to leave room for personal input from the decider, otherwise, he/she will feel constrained, which is not the best way to gain acceptance of the system.

This remark is further confirmed by another strange observation, at least from the designer's point of view. If one looks carefully at Figure 4, one can see cells in the schedule 
containing the letter "P", which stands for "Problem". This appeared in the early versions of the system, whenever the program was not able to find an assignment for the day and the employee concerned. This "P" indicated that the solution proposed was not complete and that the programfailed somewhat. What was considered by the designer as a flaw, to be corrected as soon as possible, turned out not to be a nuisance for the user. Actually, the head nurses did not mind having to solve local problems by themselves, it even gave them a feeling of usefulness : a system proposing a schedule in a matter of seconds where a manual solution needed hours of pencil and eraser work was less intimidating if it needed, itself, some help. A DSS is a system supporting the decider, here it was also becoming symmetrically a system supported by the decider, therefore a cooperative system. Without going as far as saying that the "bug" becomes a "feature", it should be realized that allowing incomplete solutions, even unfeasible ones (but interactively improvable) is not always a flaw (a point of which the designer should be ashamed) and in some cases, it might be the difference that facilitates adoption and use.

\section{A RATIONALE FOR USER-CENTERED APPROACHES}

\subsection{DSS should be usable, useful and used}

Research in the DSS area always addresses decision problems, or decision processes, and aims at giving an answer in the form of a computerized artifact to support decision making. In doing so, systems proposed or developed have first to be usable, which means that a dialogue understandable by anyone provides ways of getting added value with respect to a decision to be made. However, a DSS might be the answer to a non-problem, or give answers based on assumptions that do not correspond to reality, or, more frequently, potential users discard it because it lacks important aspects of the decision situation that deciders consider unavoidable. Therefore, however usable, some systems might not be considered useful, whether for good or bad reasons. But most DSSs built can be considered useful, or potentially useful. In the latter case, a last hurdle is to have them really used in the day-to-day organizational context.

The fact that a DSS is really used is actually the "acid test" of the power of a DSS design methodology. A designer cannot blame users, managers, executives or the organization for their inability to understand how useful a system might be. He has to put this social context in the design methodology from the beginning, and not only during a short period early on when getting data on their needs or behavior. If we regroup under the term "users" the set of people and groups for whom the designer works, a constant reference to and participation of users in the whole design process is a necessary, although not sufficient, requirement if use is a measure of success.

\subsection{DSS Design cannot be separated from implementation}

Design to some extent refers to the intellectual process of conceptually building up a map of the system which will be "physically" built later on, the way an architect "thinks" and "paints" a future house or apartment complex. It is obviously common for designers (or architects) to 
take into account the context which might include the organizational setting, the financial limits, on the technological possibilities for example. But very often, these contexts are considered to be constraints to be fulfilled in the end rather than input and components of the design work. If designers aim at producing a DSS which will ultimately really be used, then the implementation phase should be planned early on in the design. Methodologies based on paradigms like "design the dialogue first" as in Sprague ROMC approach, or the "evolutive" approach which puts users in the driver's seat during the implementation and evaluation phases of the succeeding life cycles of the system being built, have therefore a good chance of ending up with systems which will really be used.

\subsection{DSS design is a change process}

Like many applications of technology to business management, DSS must be seen as the careful planning of the interactions between the technology introduced, organizational structure, activities carried on and behavior of the actors, as was emphasized by Leavitt et al (1973). Success in DSS design and implementation means that, in this socio-technical context, the coupling of the social and the technical processes which take place has been carefully managed.

Courbon and Bourgeois (1980) summarized the various approaches identifiable when trying to couple these two processes, the social one and the technical one. Figure 5 shows these two processes. The technical process can be summarized as a first phase in the analysis of the decision situation and ends up ultimately with the evaluation of the system designed, built and used. The social side is a process starting with an "awareness" phase were users come to know that some new computerized system is being studied, whether the initiative for such a system was taken by the organization or following a request they themselves made. Some social discussions will take place, and somehow, they will progressively freeze into some attitudes or expectations regarding the final delivered system.

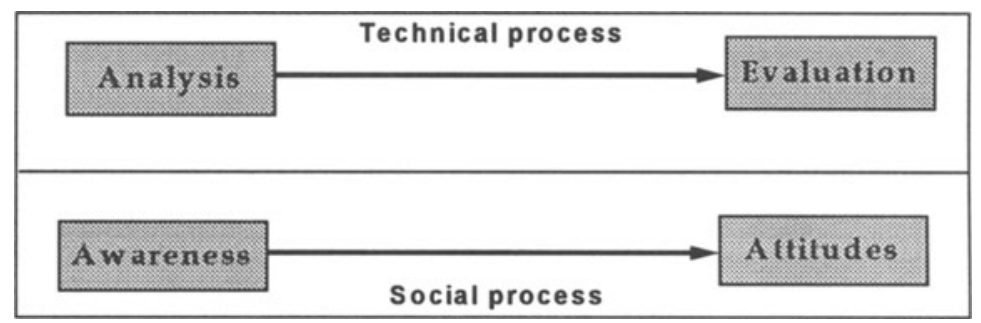

Figure 5 DSS design and implementation as a socio-technical process (Courbon and Bourgeois, 1980).

The main question for the designer is therefore to manage and couple these two processes in order to end up with a final situation where evaluation of the system (result of the technical process) is as close as possible to attitudes and expectations of users.

Coupling these two processes can be done in several ways, and Figure 6 tries to illustrate four main approaches, in a slightly caricatural and simplified way. 
The technocratic approach consists in a sequential coupling beginning with the technical process. Here, the designer somewhat "knows" what is good for the users and builds his/her system before any of them knows what is going on. The challenge is then to later manage the social process by having users informed about a new system and discuss it so that they come to expect a system with the characteristics of the one already available. There are cases where this approach can work, but chances are that users do not go follow the direction the project manager would like them to take.

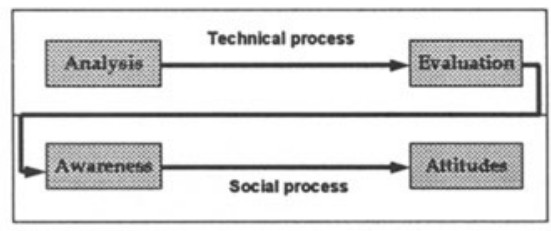

$1:$ Technocratic approach

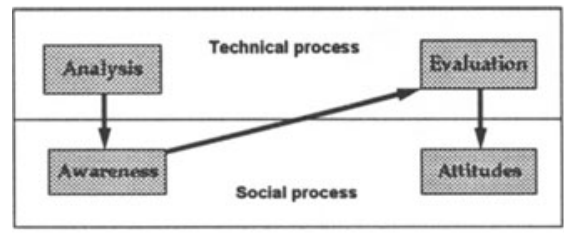

3 : Participative approach

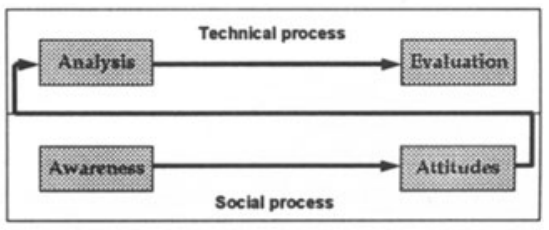

2 : System's analysis approach

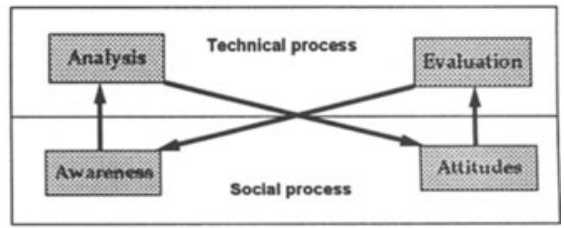

4 : Evolutive approach

Figure 6 Various approaches for coupling the technical and social change processes.

The system's analysis approach recognizes that user input is necessary, and couples the two processes sequentially, but does it the other way around. Here users are present early on and actually no technical process takes place before users come to an agreement on what the system should do. When the social process is completed, then the designer gets a set of system specifications and he/she tries to get some signature from the users on what the system should look like. Then, he/she expects the users to quietly wait for the specialists to then go into their technical process of analysis up to delivery and use. The question in this case is how to freeze this social process, especially if the technical life cycle is long : will not users continue to discuss, or change their expectations and attitudes?

A third approach is the participative one. Here there is a recognition that this two processes have to be managed parallelly rather than sequentially, that users have to be present at each stage, and that the life cycle of the technical process will permanently be enriched by participation and feedback from users (or from theirrepresentatives). The chances of a correspondance between the evaluation of the system and users' expectations are often increased.

The evolutive approach is an extension of the participative one. Here the iterative process is expressed by the loop through the four stages of the technical and social processes, which 
are therefore coupled in a continuous fashion rather than sequentially or in parallelly. Hopefully, the recurring phases of the active user's participation at each cycle will close the gap between his/her expectations and the final stabilized system delivered.

\subsection{Decision and DSS design are both learning processes}

A closer look at the last approach in the preceding section points to an interesting aspect of what a user-centered approach really is. Each cycle or interaction in prototype building is in fact a sequence of 1) action - whenever the designer implements a new version and the user works with it - and 2) reflexion, i.e. the feedback where the user and the designer think about what should be done next based on the preceding active use.

But action and reflexion are the two basic components of learning. In Piaget's terms, we acquire knowledge, starting from the date of our birth, by a first mechanism - accommodation - where we learn from "objects" we interact with and from which we empirically build adapted responses, or routines, to them ("schemes" as Piaget call them). Then, a second mechanism takes place - reflective abstraction - which happens when a mental reconstruction of all the schemes at a new level of abstraction becomes necessary. Indeed, there are situations where new "objects" cannot fit anymore with the available routines. The human being must then reconstruct and rearrange in his/her brain all his/her routines at a new level of abstraction to deal with these new, unmanageable situations.

User-centered design approach, as it has been described, therefore becomes a dual learning process. On one side, it allows the designer to learn about the user, his/her problem and behavior ; this gives the designer the opportunity to more clearly understand the nature of the decision support to be provided. On the other hand, the user, through his/her repeated use and analysis of it comes to learn about the system progressively built, thus increasing the probability of appropriation of the DSS by the user. Moreover, during this process, the user will also learn about his/her own decision making abilities and/or shortcomings. Often, being implicated in the design and implementation of the DSS will be, for the user, as valuable as the finished product.

One of the reasons why a user-centered approach to DSS design increases the chances of success comes from this implicit nature of user-centered DSS design as a shared learning experience.

\subsection{Decision processes are a lot more than intelligence, design and choice}

The DSS field has long been influenced by Simon's model of decision process. Departing from the view of a decision maker as a rational person who optimizes some objective function, he introduced the notion of bounded rationality. Here, decision is viewed as a sequence of, and iteration through, three phases : intelligence - problem finding and identification -, design where alternatives are generated and evaluated - and choice - which takes place in a process where the decision maker merely tries to arrive at a satisficing solution. Indeed, such a vision appeared to be very fruitful and in part justified the emergence of DSSs themselves which found their legitimacy in the support they tried to provide in these three phases, and not only in the choice one. 
But there is a limit to what this model can account for when looking at decisions as they are made in an economy and in organizational settings as they are evolving nowadays. We will refer here to a challenging view of managerial decision making recently proposed by Langley, Mintzberg et al. (1995). They contend that, up to now, decision making has been considered either as a sequential process, driven by diagnosis (Simon's classic model), or as anarchical, driven by events as in the so-called "garbage-can" model, or, a mix of both of them, as an iterative process, driven by diagnosis and interrupted by events.

The authors consider that the mainstream thinking about decision making suffers from three limitations, 1) reification because decision is in fact a "construct" reflecting the observer bias, 2) dehumanization because actually "decision makers play a central role as creators, actors and carriers, and organizational decision processes are often driven by the forces of affect, insight and inspiration", and 3) isolation because decision analysts tend to address well identified decision processes whereas "[strategic] decision processes are characterized more by their interrelations and linkages than by their isolation".

Looking at these three criticisms from the DSS designer's point of view can lead to a new understanding of what DSS are useful for when opening up the concepts of decision, decision maker and the decision making process.

The first criticism, reification, warns us against trying too hard to identify problem diagnosis and solution seeking by suggesting that commitment to action, which we tend to consider as concrete and real decision to be supported, is more a construct of the outside observer and is more diluted and evasive than we would like it to be. In most cases, decision is in fact the exploration of issues which, sometimes, progressively converges toward a problem and an action. Decision support here is more an information and communication environment which helps this issue thinking and "toying". If one considers, for example, the field of EIS (Executive Information Systems), a clear type of DSS, it is easy to observe that an EIS does not contain much hard decision support. Usually, an EIS is a platform which presents synthetic indicators and allows easy exploration of them. Indeed, it has been summarized as a "What is ?" tool rather than a "What if ?" one. In this case, the user-centered approach is obvious and testimonied by the usual existence of a few EIS designers working directly with executives to build them "screens" following their questioning and issue concerns. Often, the real value of these EISs lies in the focus on issues that executives want the organization to deal with by "showing" managers which strategic directions concern top management.

"Opening up the decision maker", as Langley et al. invite us to do, means that a decider is more than a rational, even a limited one, or a "cerebral" as they call it, human being. The authors propose an alternative model of decision making as an insightful, driven by inspiration process. Intuition is a very difficult phenomenon to understand, but it probably plays an important role any time a decision maker gets a sudden grasp of a whole situation and somewhat cristallizes or orients in a specific direction his/her, and others, thinking about an issue or a problem. What can information systems and DSSs do regarding this elusive behavior to support it ? Probably not much, but any contribution, however limited, is likely to generate important added value.

Let us propose here some research tracks along the idea of investigating the useful metaphors (in the sense of Sprague's ROMC approach) that, for a decider, might trigger intuition and insight. We suggest that the "network", "battlefield" and "chaos" metaphors are prospective candidates for decision support in this line of research. Executives tend to think in 
terms of networks, for example in the field of financial links among companies of interest, of experts from various origins, of power people or university alumni, of logistics and flows of cash and goods, or of company organizational charts. Maintenance and exploration of these computer supported networks might be a base for this intuitive reasoning. Battlefield animation relates to the fact that executives are usually involved in several strategic projects (competitor take-over, subsidiary creation with other companies, big contract negotiation, technology adoption, etc.) which develop over months and interact with each other. Visualization of selected information pertaining to these undertakings might be of some help, and multimedia DSS is probably part of the answer. The chaos metaphor is even more speculative, because it rests upon a theory of the shape of evolution, of trends, of discontinuities and irreversibilities which, intuitively and implicitly, corresponds to an executive struggle with the vision of the future to forecast, prevent or build. Here also it is obvious that any investigation depends on a thorough user-orientation in DSS design and implementation.

\subsection{Decision support is becoming communication support}

The last criticism of Langley et al concerns the tendency of researchers and practitioners to isolate decision making processes, whereas they rightfully consider that in reality they are characterized by numerous linkages between interrelated issue streams. These linkages can be sequential, conditional or coordinating ones, and providing a support locally may lead to the significance of the overall intricacies of these dependencies being lost. However, broadening the scope of decision support has a good chance of ending up with overly complex systems, or unmanageable ones, or ones having an unreasonable cost.

But if one considers that the overall picture of decision making processes linkages is to be taken into account for decision support, we have to put it in the perspective of managers communicating between themselves and among issue streams. This means that, not surprisingly, decision processes such as related issue streams monitoring are actually a collaborative activity, and therefore group-oriented. It follows that decision support will evolve toward communication support. The field of Group-DSS has already brought valuable results, although most of them fall into the category of interactive Electronic Meeting Support (EMS). However, issue streams extend over lengthy periods and EMSs leave a lot of activity in-between formal meetings.

It is our belief that DSS has a lot to gain from incorporation of groupware functionalities to feel this gap. In fact, we can argue that more and more, traditional decision support will appear as complements, even software components, indeed very useful ones, of systems deeply rooted in the groupware category. Technologies in this field are numerous, for example shared document data bases, conferencing, workflow applications, application sharing and videoconferencing besides electronic messaging, group scheduling and project planning. But here again, technology only comes second to organizational development issues and user participation in system design and implementation. 


\section{REFERENCES}

Becker, K. (1993) Reusable frameworks for Decision Support Systems development, unpublished PhD Thesis, University of Namur, Belgium.

Bonczek R.H., Holsapple C.W. and Whinston A.B. (1981), Foundations of Decision Support Systems, Academic Press, Orlando.

Carlson E.D., Grace B.F. and Sutton J.A. (1977) Case studies of end-user requirements for interactive problem solving systems, MIS Quarterly, Vol 1, No 1, March.

Courbon, J-C., Grajew, J. and Tolovi, J. (1979) L'approche évolutive dans la conception et la mise en œuvre des Systèmes Interactifs d'Aide à la Décision, Informatique et Gestion, Janvier-Février.

Courbon, J-C. and Bourgeois M. (1980) The information System Designer as a Nurturing Agent of a Socio-Technical System, in The Information System Environment, H. Lucas et al. Eds, North Holland.

Courbon, J-C. and Esaki, J-C. (1992) User-driven Functional Specifications for Decision Support Systems : the Case of a Nurse-Scheduling DSS, in Economics/Management of Information Technology, CEMIT/CECOIA3 Conference Proceedings, Tokyo.

Esaki, J-C. (1995) Conception et réalisation de systèmes interactifs d'aide à la décision orientés-objet : cas d'un planning infirmier, unpublished $\mathrm{PhD}$ Thesis, University of Geneva, Switzerland.

Gerrity, T. (1975) Design of man-machine decision systems : an application to portfolio management, Sloan Management Review, Vol 12, No 3, Winter.

Keen, P.G.W. and Scott-Morton, M.S. (1978) Decision Support Systems : an organizational perspective, Addison Wesley, Reading.

Keen, P.G.W. (1981) Adative design, ACM Transactions, Data Base, Winter.

Langley, A., Mintzberg, H., Picher, P., Posada E. and Saint-Macary J. (1995) Opening up Decision Making: The View from the Black Stool, Organization Science, Vol. 6, No. 3, May-June.

Leavitt, H.J., Dill, W.R. and Eyring, H.B. (1973) The organizational world : a systematic view of managers and management, Harcourt Brace Jovanovich.

Martin, J. (1991) Rapid Application Development, Mac-Millan.

Ness, D. (1975) Interactive systems : theories of design, Joint Wharton/DNR Conference on Interactive Information and DSS, The Wharton School.

Piaget, J. (xxxx), L'abstraction réfléchissante,

Scott-Morton, M.S. (1971) Management decision systems : computer-based support for decision making, Harvard University Press, Cambridge.

Srague, R. and Carlson E. (1982) Building effective decision support systems, Prentice Hall.

Stabell, C. (1988) Towards a theory of decision support, in Proceedings of DSS-88, Weber S. Ed.

Zarate, P. (1991) Conception et mise en oeuvre de Systèmes Interactifs d'Aide à la Décision : application à l'élaboration des plannings de repos du personnel navigant, unpublished $\mathrm{PhD}$ Thesis, University of Paris IX Dauphine, France. 


\section{BIOGRAPHY}

Jean-Claude Courbon has been Professor of Information Systems at the Institut National des Télécommunications (Evry, France) since 1992. He got an engineering degree from Ecoles des Mines de St Etienne (1964) and a PhD in Business Administration from the University of Texas at Austin (1974). After working as an engineer in the oil business for 6 years for Total, he taught at the University of Grenoble, HEC in Montréal before becoming Professor at the University of Geneva for 12 years. His research has long been in the DSS field, end-user computing and Computer Assisted Learning. More recently, his interests moved to EIS (Executive Information Systems) as well as Group DSS and Groupware. 